\title{
Pluralism in Evolutionary Theory
}

Ulf Dieckmann (dieckmann @iiasa.ac.at)

Michael Doebeli (doebeli@zoology.ubc.ca)

\section{Approved by}

Leen Hordijk

Director, IIASA

March 2005

Interim Reports on work of the International Institute for Applied Systems Analysis receive only limited review. Views or opinions expressed herein do not necessarily represent those of the Institute, its National Member Organizations, or other organizations supporting the work. 


\section{IIASA STUDIES IN ADAPTIVE DYNAMICS No. 91}

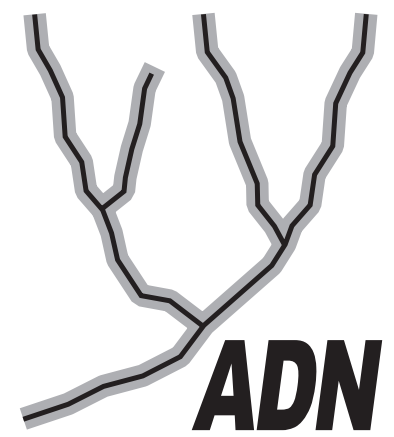

The Adaptive Dynamics Network at IIASA fosters the development of new mathematical and conceptual techniques for understanding the evolution of complex adaptive systems.

Focusing on these long-term implications of adaptive processes in systems of limited growth, the Adaptive Dynamics Network brings together scientists and institutions from around the world with IIASA acting as the central node.

Scientific progress within the network is collected in the IIASA Studies in Adaptive Dynamics series.

No. 1 Metz JAJ, Geritz SAH, Meszéna G, Jacobs FJA, van Heerwaarden JS: Adaptive Dynamics: A Geometrical Study of the Consequences of Nearly Faithful Reproduction. IIASA Working Paper WP-95-099 (1995). van Strien SJ, Verduyn Lunel SM (eds): Stochastic and Spatial Structures of Dynamical Systems, Proceedings of the Royal Dutch Academy of Science (KNAW Verhandelingen), North Holland, Amsterdam, pp. 183-231 (1996).

No. 2 Dieckmann U, Law R: The Dynamical Theory of Coevolution: A Derivation from Stochastic Ecological Processes. IIASA Working Paper WP-96-001 (1996). Journal of Mathematical Biology 34:579-612 (1996).

No. 3 Dieckmann U, Marrow P, Law R: Evolutionary Cycling of Predator-PreyInteractions: Population Dynamics and the Red Queen. IIASA Preprint (1995). Journal of Theoretical Biology 176:91-102 (1995).

No. 4 Marrow P, Dieckmann U, Law R: Evolutionary Dynamics of Predator-Prey Systems: An Ecological Perspective. IIASA Working Paper WP-96-002 (1996). Journal of Mathematical Biology 34:556-578 (1996).

No. 5 Law R, Marrow P, Dieckmann U: On Evolution under Asymmetric Competition. IIASA Working Paper WP-96-003 (1996). Evolutionary Ecology 11:485-501 (1997).

No. 6 Metz JAJ, Mylius SD, Diekmann O: When Does Evolution Optimize? On the Relation Between Types of Density Dependence and Evolutionarily Stable Life History Parameters. IIASA Working Paper WP-96-004 (1996).

No. 7 Ferrière R, Gatto M: Lyapunov Exponents and the Mathematics of Invasion in Oscillatory or Chaotic Populations. Theoretical Population Biology 48:126-171 (1995).

No. 8 Ferrière R, Fox GA: Chaos and Evolution. IIASA Preprint (1996). Trends in Ecology and Evolution 10:480485 (1995).

No. 9 Ferrière R, Michod RE: The Evolution of Cooperation in Spatially Heterogeneous Populations. IIASA Working Paper WP-96-029 (1996). The American Naturalist 147:692717 (1996).

No. 10 van Dooren TJM, Metz JAJ: Delayed Maturation in Temporally Structured Populations with Non-Equilibrium Dynamics. IIASA Working Paper WP-96-070 (1996). Journal of Evolutionary Biology 11:41-62 (1998).
No. 11 Geritz SAH, Metz JAJ, Kisdi É, Meszéna G: The Dynamics of Adaptation and Evolutionary Branching. IIASA Working Paper WP-96-077 (1996). Physical Review Letters 78:2024-2027 (1997).

No. 12 Geritz SAH, Kisdi É, Meszéna G, Metz JAJ: Evolutionary Singular Strategies and the Adaptive Growth and Branching of the Evolutionary Tree. IIASA Working Paper WP-96-114 (1996). Evolutionary Ecology 12:35-57 (1998).

No. 13 Heino M, Metz JAJ, Kaitala V: Evolution of Mixed Maturation Strategies in Semelparous Life-Histories: The Crucial Role of Dimensionality of Feedback Environment. IIASA Working Paper WP-96-126 (1996). Philosophical Transactions of the Royal Society of London Series B 352:1647-1655 (1997).

No. 14 Dieckmann U: Can Adaptive Dynamics Invade? IIASA Working Paper WP-96-152 (1996). Trends in Ecology and Evolution 12:128-131 (1997).

No. 15 Meszéna G, Czibula I, Geritz SAH: Adaptive Dynamics in a 2-Patch Environment: A Simple Model for Allopatric and Parapatric Speciation. IIASA Interim Report IR-97-001 (1997). Journal of Biological Systems 5:265-284 (1997).

No. 16 Heino M, Metz JAJ, Kaitala V: The Enigma of Frequency-Dependent Selection. IIASA Interim Report IR97-061 (1997). Trends in Ecology and Evolution 13:367-370 (1998).

No. 17 Heino M: Management of Evolving Fish Stocks. IIASA Interim Report IR-97-062 (1997). Canadian Journal of Fisheries and Aquatic Sciences 55:1971-1982 (1998).

No. 18 Heino M: Evolution of Mixed Reproductive Strategies in Simple Life-History Models. IIASA Interim Report IR-97063 (1997).

No. 19 Geritz SAH, van der Meijden E, Metz JAJ: Evolutionary Dynamics of Seed Size and Seedling Competitive Ability. IIASA Interim Report IR-97-071 (1997). Theoretical Population Biology 55:324-343 (1999).

No. 20 Galis F, Metz JAJ: Why Are There So Many Cichlid Species? On the Interplay of Speciation and Adaptive Radiation. IIASA Interim Report IR-97-072 (1997). Trends in Ecology and Evolution 13:1-2 (1998). 
No. 21 Boerlijst MC, Nowak MA, Sigmund K: Equal Pay for all Prisoners/ The Logic of Contrition. IIASA Interim Report IR-97-073 (1997). American Mathematical Society Monthly 104:303-307 (1997). Journal of Theoretical Biology 185:281-293 (1997).

No. 22 Law R, Dieckmann U: Symbiosis Without Mutualism and the Merger of Lineages in Evolution. IIASA Interim Report IR-97-074 (1997). Proceedings of the Royal Society of London Series B 265:1245-1253 (1998).

No. 23 Klinkhamer PGL, de Jong TJ, Metz JAJ: Sex and Size in Cosexual Plants. IIASA Interim Report IR-97-078 (1997). Trends in Ecology and Evolution 12:260-265 (1997).

No. 24 Fontana W, Schuster P: Shaping Space: The Possible and the Attainable in RNA Genotype-Phenotype Mapping. IIASA Interim Report IR-98-004 (1998). Journal of Theoretical Biology 194:491-515 (1998).

No. 25 Kisdi É, Geritz SAH: Adaptive Dynamics in Allele Space: Evolution of Genetic Polymorphism by Small Mutations in a Heterogeneous Environment. IIASA Interim Report IR-98-038 (1998). Evolution 53:993-1008 (1999).

No. 26 Fontana W, Schuster P: Continuity in Evolution: On the Nature of Transitions. IIASA Interim Report IR-98-039 (1998). Science 280:1451-1455 (1998).

No. 27 Nowak MA, Sigmund K: Evolution of Indirect Reciprocity by Image Scoring/ The Dynamics of Indirect Reciprocity. IIASA Interim Report IR-98-040 (1998). Nature 393:573-577 (1998). Journal of Theoretical Biology 194:561574 (1998).

No. 28 Kisdi É: Evolutionary Branching Under Asymmetric Competition. IIASA Interim Report IR-98-045 (1998). Journal of Theoretical Biology 197:149-162 (1999).

No. 29 Berger U: Best Response Adaptation for Role Games. IIASA Interim Report IR-98-086 (1998).

No. 30 van Dooren TJM: The Evolutionary Ecology of Dominance-Recessivity. IIASA Interim Report IR-98-096 (1998). Journal of Theoretical Biology 198:519-532 (1999).

No. 31 Dieckmann U, O'Hara B, Weisser W: The Evolutionary Ecology of Dispersal. IIASA Interim Report IR-98-108 (1998). Trends in Ecology and Evolution 14:88-90 (1999).

No. 32 Sigmund K: Complex Adaptive Systems and the Evolution of Reciprocation. IIASA Interim Report IR-98-100 (1998). Ecosystems 1:444-448 (1998).

No. 33 Posch M, Pichler A, Sigmund K: The Efficiency of Adapting Aspiration Levels. IIASA Interim Report IR-98103 (1998). Proceedings of the Royal Society London Series B 266:1427-1435 (1999).

No. 34 Mathias A, Kisdi É: Evolutionary Branching and Coexistence of Germination Strategies. IIASA Interim Report IR-99-014 (1999).

No. 35 Dieckmann U, Doebeli M: On the Origin of Species by Sympatric Speciation. IIASA Interim Report IR-99-013 (1999). Nature 400:354-357 (1999).

No. 36 Metz JAJ, Gyllenberg M: How Should We Define Fitness in Structured Metapopulation Models? Including an Application to the Calculation of Evolutionarily Stable Dispersal Strategies. IIASA Interim Report IR-99-019 (1999). Proceedings of the Royal Society of London Series B 268:499508 (2001)
No. 37 Gyllenberg M, Metz JAJ: On Fitness in Structured Metapopulations. IIASA Interim Report IR-99-037 (1999). Journal of Mathematical Biology 43:545-560 (2001).

No. 38 Meszéna G, Metz JAJ: Species Diversity and Population Regulation: The Importance of Environmental Feedback Dimensionality. IIASA Interim Report IR-99-045 (1999).

No. 39 Kisdi É, Geritz SAH: Evolutionary Branching and Sympatric Speciation in Diploid Populations. IIASA Interim Report IR-99-048 (1999).

No. 40 Ylikarjula J, Heino M, Dieckmann U: Ecology and Adaptation of Stunted Growth in Fish. IIASA Interim Report IR-99-050 (1999). Evolutionary Ecology 13:433-453 (1999).

No. 41 Nowak MA, Sigmund K: Games on Grids. IIASA Interim Report IR-99-038 (1999). Dieckmann U, Law R, Metz JAJ (eds): The Geometry of Ecological Interactions: Simplifying Spatial Complexity, Cambridge University Press, Cambridge, UK, pp. 135-150 (2000).

No. 42 Ferrière R, Michod RE: Wave Patterns in Spatial Games and the Evolution of Cooperation. IIASA Interim Report IR-99-041 (1999). Dieckmann U, Law R, Metz JAJ (eds): The Geometry of Ecological Interactions: Simplifying Spatial Complexity, Cambridge University Press, Cambridge, UK, pp. 318-332 (2000).

No. 43 Kisdi É, Jacobs FJA, Geritz SAH: Red Queen Evolution by Cycles of Evolutionary Branching and Extinction. IIASA Interim Report IR-00-030 (2000). Selection 2:161176 (2001).

No. 44 Meszéna G, Kisdi É, Dieckmann U, Geritz SAH, Metz JAJ: Evolutionary Optimisation Models and Matrix Games in the Unified Perspective of Adaptive Dynamics. IIASA Interim Report IR-00-039 (2000). Selection 2:193-210 (2001).

No. 45 Parvinen K, Dieckmann U, Gyllenberg M, Metz JAJ: Evolution of Dispersal in Metapopulations with Local Density Dependence and Demographic Stochasticity. IIASA Interim Report IR-00-035 (2000). Journal of Evolutionary Biology $16: 143-153$ (2003).

No. 46 Doebeli M, Dieckmann U: Evolutionary Branching and Sympatric Speciation Caused by Different Types of Ecological Interactions. IIASA Interim Report IR-00-040 (2000). The American Naturalist 156:S77-S101 (2000).

No. 47 Heino M, Hanski I: Evolution of Migration Rate in a Spatially Realistic Metapopulation Model. IIASA Interim Report IR-00-044 (2000). The American Naturalist 157:495511 (2001).

No. 48 Gyllenberg M, Parvinen K, Dieckmann U: Evolutionary Suicide and Evolution of Dispersal in Structured Metapopulations. IIASA Interim Report IR-00-056 (2000). Journal of Mathematical Biology 45:79-105 (2002).

No. 49 van Dooren TJM: The Evolutionary Dynamics of Direct Phenotypic Overdominance: Emergence Possible, Loss Probable. IIASA Interim Report IR-00-048 (2000). Evolution 54: 1899-1914 (2000).

No. 50 Nowak MA, Page KM, Sigmund K: Fairness Versus Reason in the Ultimatum Game. IIASA Interim Report IR00-57 (2000). Science 289:1773-1775 (2000).

No. 51 de Feo O, Ferrière R: Bifurcation Analysis of Population Invasion: On-Off Intermittency and Basin Riddling. IIASA Interim Report IR-00-074 (2000). International Journal of Bifurcation and Chaos 10:443-452 (2000). 
No. 52 Heino M, Laaka-Lindberg S: Clonal Dynamics and Evolution of Dormancy in the Leafy Hepatic Lophozia Silvicola. IIASA Interim Report IR-01-018 (2001). Oikos 94:525-532 (2001).

No. 53 Sigmund K, Hauert C, Nowak MA: Reward and Punishment in Minigames. IIASA Interim Report IR-01-031 (2001). Proceedings of the National Academy of Sciences of the USA 98:10757-10762(2001).

No. 54 Hauert C, De Monte S, Sigmund K, Hofbauer J: Oscillations in Optional Public Good Games. IIASA Interim Report IR-01-036 (2001).

No. 55 Ferrière R, Le Galliard J: Invasion Fitness and Adaptive Dynamics in Spatial Population Models. IIASA Interim Report IR-01-043 (2001). Clobert J, Dhondt A, Danchin E, Nichols J (eds): Dispersal, Oxford University Press, pp. 57-79 (2001).

No. 56 de Mazancourt C, Loreau M, Dieckmann U: Can the Evolution of Plant Defense Lead to Plant-Herbivore Mutualism. IIASA Interim Report IR-01-053 (2001). The American Naturalist 158: 109-123 (2001).

No. 57 Claessen D, Dieckmann U: Ontogenetic Niche Shifts and Evolutionary Branching in Size-Structured Populations. IIASA Interim Report IR-01-056 (2001). Evolutionary Ecology Research 4:189-217 (2002).

No. 58 Brandt H: Correlation Analysis of Fitness Landscapes. IIASA Interim Report IR-01-058 (2001).

No. 59 Dieckmann U: Adaptive Dynamics of Pathogen-Host Interacations. IIASA Interim Report IR-02-007 (2002). Dieckmann U, Metz JAJ, Sabelis MW, Sigmund K (eds): Adaptive Dynamics of Infectious Diseases: In Pursuit of Virulence Management, Cambridge University Press, Cambridge, UK, pp. 39-59 (2002).

No. 60 Nowak MA, Sigmund K: Super- and Coinfection: The Two Extremes. IIASA Interim Report IR-02-008 (2002). Dieckmann U, Metz JAJ, Sabelis MW, Sigmund K (eds): Adaptive Dynamics of Infectious Diseases: In Pursuit of Virulence Management, Cambridge University Press, Cambridge, UK, pp. 124-137 (2002).

No. 61 Sabelis MW, Metz JAJ: Perspectives for Virulence Management: Relating Theory to Experiment. IIASA Interim Report IR-02-009 (2002). Dieckmann U, Metz JAJ, Sabelis MW, Sigmund K (eds): Adaptive Dynamics of Infectious Diseases: In Pursuit of Virulence Management, Cambridge University Press, Cambridge, UK, pp. 379-398 (2002).

No. 62 Cheptou P, Dieckmann U: The Evolution of SelfFertilization in Density-Regulated Populations . IIASA Interim Report IR-02-024 (2002). Proceedings of the Royal Society of London Series B 269:1177-1186 (2002).

No. 63 Bürger R: Additive Genetic Variation Under Intraspecific Competition and Stabilizing Selection: A Two-Locus Study. IIASA Interim Report IR-02-013 (2002). Theoretical Population Biology 61:197-213 (2002).

No. 64 Hauert C, De Monte S, Hofbauer J, Sigmund K: Volunteering as Red Queen Mechanism for Co-operation in Public Goods Games. IIASA Interim Report IR-02-041 (2002). Science 296:1129-1132(2002).

No. 65 Dercole F, Ferrière R, Rinaldi S: Ecological Bistability and Evolutionary Reversals under Asymmetrical Competition. IIASA Interim Report IR-02-053 (2002). Evolution 56:1081-1090 (2002).
No. 66 Dercole F, Rinaldi S: Evolution of Cannibalistic Traits: Scenarios Derived from Adaptive Dynamics. IIASA Interim Report IR-02-054 (2002). Theoretical Population Biology 62:365-374 (2002).

No. 67 Bürger R, Gimelfarb A: Fluctuating Environments and the Role of Mutation in Maintaining Quantitative Genetic Variation. IIASA Interim Report IR-02-058 (2002). Genetical Research 80:31-46 (2002).

No. 68 Bürger R: On a Genetic Model of Intraspecific Competition and Stabilizing Selection. IIASA Interim Report IR02-062 (2002). Amer. Natur. 160:661-682 (2002).

No. 69 Doebeli M, Dieckmann U: Speciation Along Environmental Gradients. IIASA Interim Report IR-02-079 (2002). Nature 421:259-264 (2003).

No. 70 Dercole F, Irisson J, Rinaldi S: Bifurcation Analysis of a Prey-Predator Coevolution Model. IIASA Interim Report IR-02-078 (2002). SIAM Journal on Applied Mathematics 63:1378-1391 (2003).

No. 71 Le Galliard J, Ferrière R, Dieckmann U: The Adaptive Dynamics of Altruism in Spatially Heterogeneous Populations. IIASA Interim Report IR-03-006 (2003). Evolution 57:1-17 (2003).

No. 72 Taborsky B, Dieckmann U, Heino M: Unexpected Discontinuities in Life-History Evolution under SizeDependent Mortality. IIASA Interim Report IR-03-004 (2003). Proceedings of the Royal Society of London Series B 270:713-721 (2003).

No. 73 Gardmark A, Dieckmann U, Lundberg P: LifeHistory Evolution in Harvested Populations: The Role of Natural Predation. IIASA Interim Report IR-03-008 (2003). Evolutionary Ecology Research 5:239-257 (2003).

No. 74 Mizera F, Meszéna G: Spatial Niche Packing, Character Displacement and Adaptive Speciation Along an Environmental Gradient. IIASA Interim Report IR-03-062 (2003). Evolutionary Ecology Research 5: 363-382 (2003).

No. 75 Dercole F: Remarks on Branching-Extinction Evolutionary Cycles. IIASA Interim Report IR-03-075 (2003). Journal of Mathematical Biology 47: 569-580 (2003).

No. 76 Hofbauer J, Sigmund K: Evolutionary Game Dynamics. IIASA Interim Report IR-03-078 (2003). Bulletin of the American Mathematical Society 40: 479-519 (2003).

No. 77 Ernande B, Dieckmann U, Heino M: Adaptive Changes in Harvested Populations: Plasticity and Evolution of Age and Size at Maturation. IIASA Interim Report IR03-058 (2003). Proceedings of the Royal Society of London Series B-Biological Sciences, 271: 415-423 (2004).

No. 78 Hanski I, Heino M: Metapopulation-Level Adaptation of Insect Host Plant Preference and Extinction-Colonization Dynamics in Heterogeneous Landscapes. IIASA Interim Report IR-03-028 (2003). Theoretical Population Biology 63:309-338 (2003).

No. 79 van Doorn G, Dieckmann U, Weissing FJ: Sympatric Speciation by Sexual Selection: A Critical Re-Evaluation. IIASA Interim Report IR-04-003 (2004). American Naturalist 163: 709-725 (2004).

No. 80 Egas M, Dieckmann U, Sabelis MW: Evolution Restricts the Coexistence of Specialists and Generalists - the Role of Trade-off Structure. IIASA Interim Report IR-04-004 (2004). American Naturalist 163: 518-531 (2004). 
No. 81 Ernande B, Dieckmann U: The Evolution of Phenotypic Plasticity in Spatially Structured Environments: Implications of Intraspecific Competition, Plasticity Costs, and Environmental Characteristics. IIASA Interim Report IR-04-006 (2004). Journal of Evolutionary Biology 17 (3): 613-628 (2004).

No. 82 Cressman R, Hofbauer J: Measure Dynamics on a One-Dimensional Continuous Trait Space: Theoretical Foundations for Adaptive Dynamics. IIASA Interim Report IR04-016 (2004).

No. 83 Cressman R: Dynamic Stability of the Replicator Equation with Continuous Strategy Space. IIASA Interim Report IR-04-017 (2004).

No. 84 Ravigné V, Olivieri I, Dieckmann U: Implications of Habitat Choice for Protected Polymorphisms. IIASA Interim Report IR-04-005 (2004). Evolutionary Ecology Research 6: 125-145 (2004).

No. 85 Nowak MA, Sigmund K: Evolutionary Dynamics of Biological Games. IIASA Interim Report IR-04-013 (2004). Science 303: 793-799 (2004).
No. 86 Vukics A, Asbóth J, Meszéna G: Speciation in Multidimensional Evolutionary Space. IIASA Interim Report IR-04-028 (2004). Physical Review E 684 (2003).

No. 87 de Mazancourt C, Dieckmann U: Trade-off Geometries and Frequency-dependent Selection. IIASA Interim Report IR-04-039 (2004).

No. 88 Cadet CR, Metz JAJ, Klinkhamer PGL: Size and the Not-So-Single Sex: disentangling the effects of size on sex allocation. IIASA Interim Report IR-04-084 (2004). American Naturalist, 164: 779-792 (2004).

No. 89 Rueffler C, van Dooren TJM, Metz JAJ: Adaptive Walks on Changing Landscapes: Levins' Approach Extended. IIASA Interim Report IR-04-083 (2004). Theoretical Population Biology, 65: 165-178 (2004).

No. 90 de Mazancourt C, Loreau M, Dieckmann U: Understanding Mutualism When There is Adaptation to the Partner. IIASA Interim Report IR-05-016 (2005).

No. 91 Dieckmann U, Doebeli M: Pluralism in Evolutionary Theory. IIASA Interim Report IR-05-017 (2005).

Issues of the IIASA Studies in Adaptive Dynamics series can be obtained at www.iiasa.ac.at/Research/ADN/Series.html or by writing to adn@iiasa.ac.at. 


\section{Contents}

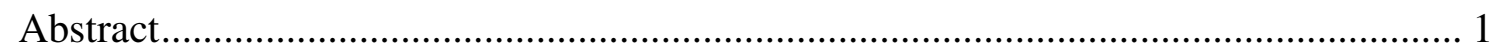

A plea for interfaced pluralism in evolutionary theory …......................................... 1

Origin and maintenance of genetic variation............................................................. 3

Definition of fitness and resulting evolutionary dynamics.......................................... 4

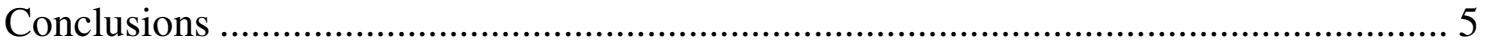

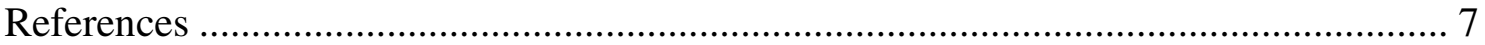




\title{
Pluralism in Evolutionary Theory
}

\author{
Ulf Dieckmann $^{1}$ and Michael Doebeli ${ }^{2}$ \\ ${ }^{1}$ Adaptive Dynamics Network, International Institute for Applied Systems Analysis, A-2361 Laxenburg, Austria. \\ Emaildieckmann@iiasa.ac.at.Phone+43-2236-807-386. \\ ${ }^{2}$ Departments of Zoology and Mathematics, University of British Columbia, 6270 University Boulevard, Van- \\ couver, BC V6T 1Z4, Canada. Email doebeli@zoology.ubc.ca. Phone+1-604-822-3326.
}

The review by Waxman and Gavrilets (Waxman and Gavrilets 2005) illustrates the collision of different mindsets in evolutionary theory. These differences originate from the aweinspiring complexity of the evolutionary process itself: evolutionary understanding critically depends on processes at many biological levels. Starting out with base pairs and their sequences, scholars of evolution have to consider - in the order of ascending biological complexity - alleles, quantitative allelic traits, physiological and morphological traits, lifehistory traits, demographic rates, fitness, changes in genotype frequencies, population dynamics, trait substitution sequences, and population bifurcations, to eventually arrive at the levels of ecological communities and the biosphere. It would appear that no other field of contemporary science sports comparable ambitions.

\section{A plea for interfaced pluralism in evolutionary theory}

As history abundantly illustrates, science successfully tackles challenges such as those encountered in the understanding of evolution by devising chains of theories that, step by step, traverse otherwise intractable ranges of complexity. Theories not appreciating the virtue of such level-based division of labor are bound to fail: nobody would seriously insist, for example, that phenomena in organic chemistry be explained in terms of quantum electrodynamics.

Yet, at times, one gets the impression that things are different in evolutionary theory: since quantitative evolutionary theory came into being by describing the dynamics of genotypes, there is a tendency to insist that all meaningful evolutionary models should be explicitly based at the level of genotypes and their dynamics. In practice this particular brand of 'level centrism' works best when attention is restricted to simplistic genotype-to-phenotype maps with simplistic phenotype-to-fitness maps. There certainly exist cases where genetic details are simple enough, and sufficiently well studied empirically, for genotype-to-phenotype maps to become thoroughly understood. Also phenotype-to-fitness maps may occasionally be straightforward: in animal and plant breeding, for example, complex ecological feedbacks on the evolutionary process may sometimes be tempered successfully through a breeder's tight control of the breeding environment. By contrast, in most natural settings - and certainly when it comes to long-term evolution - genetic detail is largely unknown and ecological complexity is mostly high. To insist, under such circumstances, on all evolutionary models being based on genotype dynamics would appear to be counterproductive.

Adaptive dynamics theory challenges such prescriptive stances by extending evolutionary game theory towards a dynamical theory of long-term evolution. This extension involves (a) accounting for all types of frequency- and density-dependent selection; (b) allowing for the stochastic and nonlinear dynamics of unstructured and structured populations; (c) considering continuous (not just mixed) strategies, metric characters, or quantitative traits; (d) describing dynamics driven by evolutionary innovations, as well as identifying and classifying the resulting evolutionary outcomes; and, perhaps most importantly, (e) deriving fitness from the 
underlying population dynamics. By contrast, more than 70 years after the Modern Synthesis, population genetics is still struggling to extend its gene-frequency-based models to incorporate the degrees of ecological complexity that are necessary for doing justice to long-term evolution and coevolution. (A cursory glance at how established textbooks of genetics treat frequency-dependent selection - increasingly recognized as being ubiquitous in nature - will help to appreciate the point.) In this constellation, adaptive dynamics theory may be perceived as playing down the relevance of population genetics. We think this perception would be unfortunate. Instead, it seems to be more productive to us to recognize that a diverse swath of complementary and mutually enhancing approaches is required for making progress with the diverse challenges posed by evolutionary theory.

To contribute to such progress, adaptive dynamics theory trades genetic for ecological detail. Since for questions of long-term evolution the former is almost always unknown, while the latter is essential, accepting this trade-off, and the associated focus at the phenotypic level of evolution, would appear to be a rational choice. New perspectives can thus be developed to complement previous theory and to foster a healthily diverse scientific discourse. It is because of its stance regarding this trade-off that adaptive dynamics theory at times jars with a more classical outlook, which had relegated these aspects to the fringes. At the same time, many evolutionary ecologists are thrilled by the innovative possibilities adaptive dynamics theory readily offers to them, thus underscoring the theory's innovative potential.

Having experienced the vigor that occasionally creeps into this debate, we suggest that evolutionary theory has a lot to gain from explicitly embracing a pluralism of approaches that are based, alternatively, on population genetics, quantitative genetics, adaptive dynamics, and evolutionary games. Along the astonishing spectrum from molecules to ecosystems, each of these approaches plays out its forte at different levels and for addressing different questions: population genetics is strongest in bringing out the evolutionary intricacies caused by specific genetic architectures, quantitative genetics excels at examining short-term responses to selection and breeding experiments, adaptive dynamics facilitates understanding the impacts of ecology on life-history evolution, and evolutionary games are most useful for exploring behavioral adaptations.

Pluralism, of course, must not inspire isolation. While separate traditions may be instrumental in nurturing diversity - occasionally defining temporary 'intellectual sandboxes' for innovative research - it is crucial that sufficient efforts be devoted to strengthening the interfaces. These are located, in general, where complexity steps up from one level to the next. A classical example is the science of the hydrogen molecule, which is poised right at the interface between (quantum) physics and (inorganic) chemistry. Clearly, connections must be forged from across both sides of such a disciplinary boundary if areas of fruitful overlap are to become as wide and as well understood as possible.

We now proceed to examine aspects of Waxman and Gavrilets' review (written by authors who have not contributed to the field they strive to portray) with this commendation of interfaced pluralism in mind. In fact, the tensions at the interface between complementary approaches to describing evolution are fully apparent in Waxman and Gavrilets' writing with regard to two fundamental aspects of evolutionary theory: the origin and maintenance of genetic diversity, and the definition of fitness and its dynamic consequences. Naturally, complementary approaches deal with these issues in different ways, and disciplinary biases can easily lead to misunderstandings and misinterpretations. 
93 Perhaps due their unfamiliarity with adaptive dynamics, Waxman and Gavrilets make a number of claims that require qualification. For example, their assertion that "Adaptive Dynamics methodology, based on using Eq. (1), predicts that polymorphism cannot be maintained when the singular point is locally stable" is fallacious. In fact, adaptive dynamics theory offers detailed methods for identifying and analyzing dimorphisms of this sort, at three different levels. (1) All ecologically stable dimorphisms are identified by reflecting a pairwise invasibility plot about its main diagonal and superimposing the resulting sign structure of invasion fitness onto the original one. All areas of dimorphic trait space in which the mutual invasion fitness of the two morphs is positive are thus readily identified geometrically. (2) To find out where gradual evolution in dimorphic trait space is expected to end up, i.e., to analyze dimorphic convergence stability, evolutionary isoclines (curves along which the local fitness gradient of one trait vanishes) are added to these plots (e.g., Geritz et al. 1998, 1999). (3) Finally, evolutionary stability at a dimorphic evolutionary attractor is ascertained by considering the sign of invasion fitness in its vicinity. Corresponding analytical techniques for higher-dimensional analysis are readily available (Meszéna et al. 2000; Leimar 2001). Also the fact that a "population does not necessarily approach a convergence stable equilibrium but can 'get stuck' at a polymorphic equilibrium away from the singular point" is, of course, recognized in adaptive dynamics theory (e.g., Geritz et al. 1999).

With regard to the origin of new genetic variation through mutation, the characterization of adaptive dynamics as being "based on the assumption that mutations occur rarely, and cause very small changes in existing phenotypic values" is not accurate. If the latter part of this claim were true, why would adaptive dynamics theory include pairwise invasibility plots as an important tool of analysis? Indeed, invasion fitness and pairwise invasibility plots are devised to assess the effects of mutational steps of arbitrary size. Also the assertion that "The phenotype of a mutation can take on any possible value and thus can range from $\infty>\mathrm{x}>-\infty$ " is clearly false for all phenotypic traits that are, by definition, restricted to finite intervals (e.g., Doebeli and Ruxton 1997; Parvinen et al. 2003). Furthermore, Waxman and Gavrilets claim that "In the Adaptive Dynamics literature to date, it has been implicitly assumed that beneficial mutations, i.e., those with a positive selection coefficient, will always initially increase in frequency, irrespective of the size of the selection coefficient, and irrespective of the copy number at which they occur." This is dramatically wrong. In actual fact, the dynamical description of trait substitution sequences in adaptive dynamics (e.g., Dieckmann et al. 1995; Dieckmann and Law 1996; Metz et al. 1996) is crucially based on recognizing and quantifying the fact that the typical fate of an advantageous mutant is to go extinct (Kimura 1983). This fact is also consistently emphasized in many other adaptive dynamics studies, e.g., Geritz et al. (1998, 1999). Similarly, the claim that "it is either implicitly or explicitly assumed that the distribution of the deviation of the mutant from the parental phenotype is independent of the parental phenotype" is erroneous, as a look at Dieckmann and Law (1996) will illustrate. Waxman and Gavrilets also overlooked that their observation that "once genetic drift is taken into account, the most significant mutations, as far as adaptation is concerned, may be those with intermediately sized effects" is accounted for in the description of evolutionary random walks by adaptive dynamics theory - with this very insight, in fact, serving as the basis of Equation (3.6) in Dieckmann and Law (1996). 
137 The notion of invasion fitness lies at the core of adaptive dynamics theory. Contrary to Waxman and Gavrilets' writing, invasion fitness $s$ is defined as the long-term per capita growth rate of a rare variant in the environment determined by one or more residents (Metz et al. 1992). For any resident phenotype $x$ this implies $s(x, x)=0$, rather than $s(x, x)=1$. While the discrete-time convention adopted by the authors is of course also valid (if more cumbersome), their unfaithful characterization of the existing literature might confuse some readers. Also the statement "The function $s(y, x)$ governs the dynamics of the frequency of the mutants" is incorrect, since what $s$ is governing directly is the dynamics of mutant density (or abundance), not its frequency. Similar sloppiness is apparent when, at various places in their review, Waxman and Gavrilets use the inaccurate term "locally stable" when they mean 'locally evolutionarily stable". This fosters confusion when, as in adaptive dynamics theory, several stability notions have to be considered in parallel.

In this context, the authors' admonition that practitioners of adaptive dynamics "should be more careful in inventing new terms for old concepts" sounds a bit overblown. The only underpinning for this claim comes from the authors' advice to refer to an evolutionarily singular strategy, one of the key concepts of adaptive dynamics theory, as a "stationary point", an "equilibrium point", or a "saddle point". The mere fact that Waxman and Gavrilets cannot decide themselves which of these three alternatives they actually mean to recommend already makes it obvious that the alternatives are not without problems either. In fact, this terminological misgiving touches on a key feature of adaptive dynamics. The criteria for evolutionary branching (Geritz et al. 1997) and the canonical equation of adaptive dynamics (Dieckmann and Law 1996) together result in the coupling of dynamical systems of different dimensions: a trait combination that happens to be a stable (or stationary) equilibrium point of $n$ dimensional adaptive dynamics is a saddle point of the corresponding $(n+1)$-dimensional adaptive dynamics, if and only if that combination is an evolutionary branching point. Using the notions 'stationary point' or 'equilibrium point' would also be inaccurate for another reason: evolutionarily singular strategies can be identified based on the geometry of pairwise invasibility plots alone, without considering any dynamical system. It is important to appreciate these subtleties before recommending a particular terminology.

One reason why Waxman and Gavrilets can give a relatively simple account of adaptive dynamics theory is that their review glosses over some of the more complex issues arising in realistic models. In particular, evolution often involves multiple traits: in such situations, the appealing geometric tools of one-dimensional adaptive dynamics must be complemented by suitable analytical consideration. This has led to two important lines of theory. First, the evolutionary outcomes in higher-dimensional trait spaces need to be classified according to a scheme that goes beyond what the review describes in its Table 1 (Meszéna et al. 2000; Leimar 2001). Second, the transients and outcomes of multi-dimensional adaptive dynamics are described by the canonical equation of adaptive dynamics (Dieckmann and Law 1996), which is derived as a deterministic approximation of the stochastic process resulting from trait substitution sequences (see also Leimar 2001; Champagnat et al. 2001; Durinx and Metz 2005). Only through this derivation can we understand (i) why, in mutation-limited adaptive dynamics, the rate of evolutionary change happens to be proportional to the local fitness gradient and the resident population size, and (ii) under which conditions the rate of mutation-limited evo- 
lution is independent of the partitioning of growth rates into birth and death rates - two insights that are far from obvious.

The entire review also glosses over the notion of ecological equilibria, or of more general ecological attractors, which lies at the very heart of an understanding of invasion fitness (e.g., Metz et al. 1992; Rand et al. 1993; Dieckmann and Law 1996; Jacobs and Metz 2003; Gyllenberg et al. 2003). The consequences of this omission become particularly evident in statements like "The movement downhill does not imply that the population experiences any fitness loss but rather reflects the resetting of fitnesses so that new resident population has a fitness of unity". The authors' cryptical allusion to the "resetting of fitnesses" is rooted in the traditional perspective of fitness as being defined independently of a population's resident traits and its currently attained ecological equilibrium. In actual fact, this "resetting" is nothing else than the inevitable and perfectly natural consequence of frequency- and/or densitydependent ecological interactions.

Waxman and Gavrilets suggest that when "fitness functions are not continuous functions of mutant frequency, the frequency of mutant phenotypes cannot be neglected - even initially - and may have a significant influence on the dynamics of the population. We know, however, of no concrete examples of this and it might be interesting to see this pursued further." This consideration is not well informed, for two reasons. First, the continuity of fitness functions is irrelevant here (since invasion fitness is always defined in the limit of mutant density approaching zero). Second, it should be noted that spatial ecological settings with limited dispersal provide natural examples of the type the authors refer to as being outside their knowledge: in such settings mutant individuals tend to interact strongly even while they are globally still rare. In fact, any form of group selection relies on this very principle, as a suite of studies based on adaptive dynamics theory have illustrated (e.g., van Baalen and Rand 1998; Metz and Gyllenberg 2001; Le Galliard et al. 2003).

The evolutionary dynamics resulting for a particular invasion fitness are primarily governed by the fitness gradient, $\left.\frac{\partial}{\partial y} s(y, x)\right|_{y=x}$. In this context, the statements "gradient type dynamics has been well established in population genetics [...] yet it is treated as a new development in Adaptive Dynamics" and "Such gradient-type dynamics are analogous to those studied in standard population genetics", referring to the canonical equation of adaptive dynamics (Dieckmann and Law 1996), are about as meaningful as saying that the plus signs used by economists are analogous to those used by physicists. Gradient dynamics are merely a generic type of dynamical system, whereas the biological mechanisms underlying such dynamics in population genetics and adaptive dynamics fundamentally differ. Similarly, a statement like "quantities such as fitness - a primarily population genetics concept" reflects an attitude that is perhaps akin to that of Richard Lewontin (1982), who, more than 20 years ago, decided to bestow his approval on evolutionary game theory because it "lies totally within the standard genetic structure of population genetics". Since fitness is realized by ecology in action, the need for an ecologically informed approach towards its definition seems incontrovertible.

Conclusions

221 In our view, many of the inaccuracies and omissions in Waxman and Gavrilets' review can be attributed to not acknowledging the necessity for pluralism in evolutionary theory. With less favoritism towards population genetics theory, and a more open mind to theoretical innova- 
tion, it would have been possible to provide a more accurate review of adaptive dynamics. For example, if Waxman and Gavrilets write that "It would be especially interesting to see a comprehensive comparison of empirical data and the corresponding predictions of Adaptive Dynamics", they are of course correct, since such a statement holds for all good science. Yet, such proclamations should be made with care so as not to denigrate the development of integrative and flexible theoretical frameworks, an ambition reflected also in Waxman's and 230 Gavrilets' own publication records. In a similar vein, complaints about allegedly "hidden 231 limitations and unconscious or implicit assumptions" and about the authors' impression that "quite a lot of the work in the literature on Adaptive Dynamics relies on numerical simulation" are questionable, especially since adaptive dynamics theory is the source of analytical tools, underpinned by explicit assumptions, that enabled a degree of generality that precursor theories could not achieve. Also, the sweeping allegation that "practitioners should be more open to referencing relevant recent work on evolutionary dynamics" cannot but be interpreted as patronizing. Waxman and Gavrilets refer to only one instance to back up their indiscriminate censure: the fact that previous work on parapatric speciation (Endler 1977; Caisse and Antonovics 1978; Moore 1981) "apparently was missed" by Doebeli and Dieckmann (2003). This is not very convincing since the article in question is a Nature paper with well-known restrictions on citation numbers and since Endler's work was actually quoted in that article.

Despite our reservations, and following the spirit of the discussions at the beginning of this commentary, we believe that Waxman and Gavrilets ought to be congratulated for their courage of serving as intermediaries, helping to bolster communication between the fields of population genetics and adaptive dynamics. There clearly is a need for strengthening the interface between these disciplines. It is certainly not a coincidence that Waxman and Gavrilets' article devotes much attention to speciation processes. We think that, in fact, speciation could assume a prominent role as the 'hydrogen molecule of evolutionary theory': genetic and ecological considerations are so inexorably intertwined at this interface that the necessary bridgebuilding is a genuinely rewarding challenge from both ends. It is therefore deplorable that Waxman and Gavrilets forewent backing up any of the criticisms voiced in the belligerent Section 5 of their review with results. An accompanying commentary (Doebeli and Dieckmann, this issue) refutes these unsubstantiated allegations.

If one is optimistic, one might take the article by Waxman and Gavrilets as a signal that population genetics is gradually opening itself to the promises of ecologically informed evolutionary theory. A quarter of a century ago, evolutionary game theory, notwithstanding its admirable achievements, did not quite succeed in perturbing traditional population genetics enough in the direction of ecological realism. Our hope is that, perhaps, adaptive dynamics theory will be luckier. 


\section{References}

Caisse, M. and Antonovics, J. (1978). Evolution of reproductive isolation in clinal populations. Heredity 40: 371-384

Champagnat, N., Ferrière, R. and Ben Arous, G. (2001) The canonical equation of adaptive dynamics : A mathematical view. Selection 2: 71-81

Dieckmann, U. and Doebeli, M. (1999). On the origin of species by sympatric speciation. Nature 400: $354-357$

Dieckmann, U. and Law, R. (1996). The dynamical theory of coevolution: A derivation from stochastic ecological processes. Journal of Mathematical Biology 34: 579-612

Dieckmann, U., Marrow, P. and Law, R. (1995). Evolutionary cycling in predator-prey interactions: Population dynamics and the Red Queen. Journal of Theoretical Biology 176: 91-102

Doebeli, M. and Dieckmann, U. (2000). Evolutionary branching and sympatric speciation caused by different types of ecological interactions. The American Naturalist 156: S77-S101

Doebeli, M. and Dieckmann, U. (2003). Speciation along environmental gradients. Nature 421: 259-264

Doebeli, M. and Ruxton, G.D. (1997). Evolution of dispersal rates in metapopulation models: Branching and cyclic dynamics in phenotype space. Evolution 51: 1730-1741

Durinx, M. and Metz, J.A.J. (2005). Multi-type branching processes and adaptive dynamics of structured populations. Section 7.8 in Haccou, P., Jagers, P. and Vatutin, V.: Branching Processes in Biology: Variation, Growth and Extinction. Cambridge University Press

Endler, J.A. (1977). Geographic variation, speciation and clines. Princeton, NJ: Princeton University Press

Waxman, D. and Gavrilets, S. (2005). 20 Questions on Adaptive Dynamics. Journal of Evolutionary Biology, in press

Geritz, S.A.H., Kisdi, É., Meszéna, G. and Metz, J.A.J. (1998). Evolutionarily singular strategies and the adaptive growth and branching of the evolutionary tree. Evolutionary Ecology 12: 35-57

Geritz, S.A.H., van der Meijden, E. and Metz, J.A.J. (1999). Evolutionary dynamics of seed size and seedling competitive ability. Theoretical Population Biology 55: 324-343

Geritz, S.A.H., Gyllenberg, M., Jacobs, F.J.A. and Parvinen, K. (2002). Invasion dynamics and attractor inheritance. Journal of Mathematical Biology 44: 548-560

Gyllenberg, M., Jacobs, F.J.A. and Metz, J.A.J. (2003). On the concept of attractor in community-dynamical processes II: The case of structured populations. Journal of Mathematical Biology 47: 235-248

Jacobs, F.J.A. and Metz, J.A.J. (2003). On the concept of attractor in community-dynamical processes I: The case of unstructured populations. Journal of Mathematical Biology 47: 222-234

Kimura, M. (1983). The neutral theory of molecular evolution. Cambridge, UK: Cambridge University Press

Kisdi, É. and Meszéna, G. (1992). Density dependent life history evolution in fluctuating environments. In: Clark, C.W. and Yoshimura, J. eds. Adaptation in a stochastic environment, pp. 26-62. Lecture Notes in Biomathematics 98. Berlin, Germany: Springer-Verlag

Le Galliard, J., Ferrière, R. and Dieckmann, U. (2003). The adaptive dynamics of altruism in spatially heterogeneous populations. Evolution 57: 1-17

Leimar, O. (2001). Evolutionary change and Darwinian demons. Selection 2: 65-72

Lewontin, R.C. (1982). Keeping it clean. Nature 300: 113-114

Meszéna, G., Kisdi, É., Dieckmann, U., Geritz, S.A.H. and Metz, J.A.J. (2001). Evolutionary optimisation models and matrix games in the unified perspective of adaptive dynamics. Selection 2: 193-210

Metz, J.A.J., Geritz, S.A.H., Meszéna, G., Jacobs, F.J.A. and van Heerwaarden, J.S. (1996). Adaptive dynamics: A geometrical study of the consequences of nearly faithful reproduction. In: van Strien, S.J. and Verduyn Lunel, S.M. eds. Stochastic and Spatial Structures of Dynamical Systems, pp. 183-231. Amsterdam, Netherlands: North-Holland

Metz, J.A.J. and Gyllenberg, M. (2001). How should we define fitness in structured metapopulation models? Including an application to the calculation of ES dispersal strategies. Proceedings of the Royal Society, London, Series B 268: 499-508

Metz, J.A.J., Nisbet, R.M. and Geritz, S.A.H. (1992). How should we define "fitness" for general ecological scenarios? Trends in Ecology and Evolution 7: 198-202

Moore, W.S. (1979). A single locus mass-action model of assortative mating, with comments on the process of speciation. Heredity 42: 173-186 
312 Parvinen, K., Dieckmann, U., Gyllenberg, M. and Metz, J.A.J. (2003). Evolution of dispersal in metapopulations with local density dependence and demographic stochasticity. Journal of Evolutionary Biology 16: 143-153

Rand, D.A., Wilson, H.B. and McGlade, J.M. (1994). Dynamics and evolution: evolutionarily attractors, invasion exponents and phenotype dynamics. Philosophical Transactions of the Royal Society, London, Series B 243: 261-283

van Baalen, M. and Rand, D.A. (1998). The unit of selection in viscous populations and the evolution of altruism. Journal of Theoretical Biology 193: 631-648 